\title{
Fetal hepatocyte-derived culture medium elicits adipocyte differentiation to bile duct cell lineages in a mouse model
}

\author{
HISATAKA OGAWA $^{1,2}$, MASAMITSU KONNO ${ }^{2}$, KOICHI KAWAMOTO ${ }^{1}$, \\ NAOHIRO NISHIDA ${ }^{1,2}$, JUN KOSEKI $^{3}$, TSUNEKAZU MIZUSHIMA ${ }^{1}$, TAROH SATOH $^{2}$, \\ HIDETOSHI EGUCHI ${ }^{1}$, YUICHIRO DOKI ${ }^{1}$, MASAKI MORI ${ }^{1}$ and HIDESHI ISHII ${ }^{3}$ \\ Departments of ${ }^{1}$ Gastroenterological Surgery, ${ }^{2}$ Frontier Science for Cancer and Chemotherapy and ${ }^{3}$ Cancer \\ Profiling Discovery, Graduate School of Medicine, Osaka University, Suita, Osaka 565-0871, Japan
}

Received January 18, 2016; Accepted April 5, 2016

DOI: $10.3892 /$ br.2018.1080

\begin{abstract}
Fetal cells in the developmental stages function with a distinct mechanism in comparison to adult tissues, which may be a useful source for regenerative medicine in postnatal medicine; however, the precise molecular mechanism remains to be elucidated fully. The present study investigated murine fetal hepatocytes, which were cultured in vitro, and the supernatants were used for the culture with murine adipose tissue-derived cells. Notably, the results indicated that fetal hepatocyte-derived culture medium elicits the induction of differentiation of adipose tissue-derived cells to bile duct cell lineages, but not to hepatocyte lineages in mice. This indicates that fetal cells possess the multi potentials, which are already absent in adults, and may be useful for regenerative medicine in future.
\end{abstract}

\section{Introduction}

Adipose-derived mesenchymal stem cells (ADSCs) have the potential to differentiate into numerous types of cells including adipocyte, chondrocytes, osteocytes, cardiomyocytes, vascular endotherial cells, pancreatic $\beta$ cells and hepatocyte cells (1-9). ADSCs can be obtained in high yield with minimal discomfort under local anesthesia $(10,11)$. Therefore, ADSCs are considered a useful source for regenerative therapy (12). However, in particular endodermal types of cells, the differentiation method has not been well established and differentiation efficiency is extremely low. Thus, the development of an efficient differentiation method is extremely important. Several studies

Correspondence to: Dr Masaki Mori, Department of Gastroenterological Surgery, Graduate School of Medicine, Osaka University, 2-2 Yamadaoka, Suita, Osaka 565-0871, Japan

E-mail:mmori@gesurg.med.osaka-u.ac.jp

Dr Hideshi Ishii, Department of Cancer Profiling Discovery, Graduate School of Medicine, Osaka University, 2-2 Yamadaoka, Suita, Osaka 565-0871, Japan

E-mail: hishii@gesurg.med.osaka-u.ac.jp

Key words: adipose-derived mesenchymal stem cells, hepatocyte, bile duct, conditioned medium, stem cell suggested that conditioned medium contains several undefined factors $(8,12)$. These undefined factors induce the stem cells to certain specific types of cells (1).

In the present study, ADSCs were cultured in hepatocyte-derived conditioned medium from mice of various ages and conditioned medium from hepatocyte cells. To the best of our knowledge, this is the first study to assess the differentiation of ADSCs into bile cell lineages using murine fetal hepatocyte-derived culture medium.

\section{Materials and methods}

Ethical statement. Animal studies were conducted in strict accordance with the principles and procedures approved by the Committee on the Ethics of Animal Experiments of Osaka University (Osaka, Japan).

Isolation of mouse adipose-derived stem cells. Mouse adipose tissue was obtained from 8 adult (8-12 weeks) C57BL/6JJcI mice. (Nihon Clea, Tokyo, Japan). Bilateral inguinal subcutaneous fat pad was removed, minced into sections, collected with ADSC-culture medium, centrifuged at 1,500 rpm for $5 \mathrm{~min}$ to remove cell debris, incubated in $0.1 \%$ collagenase type IV (Worthington Biochemical Corp., Lakewood, NJ, USA) and agitated in a water bath at $37^{\circ} \mathrm{C}$ for $30 \mathrm{~min}$. Subsequently, the mixture was added to ADSC-culture medium and centrifuged at $300 \mathrm{x} \mathrm{g}$ for $5 \mathrm{~min}$ to remove cell debris. The cell pellets were suspended in ASDS-culture medium and were plated at $500,000 / \mathrm{ml}$ following filtration through a $70-\mu \mathrm{m}$ cell strainer (Corning, Inc., Corning, NY, USA). The cells were cultured at $37^{\circ} \mathrm{C}$ and $5 \% \mathrm{CO}_{2}$. At $100 \%$ confluence, the cells were split. Culture media were replaced every 2 days. The ADSCs until the fourth passage were used for hepatic differentiation. The ADSC-culture medium consisted of Dulbecco's modified Eagle's medium (DMEM) containing high glucose (Nacalai Tesque, Inc., Kyoto, Japan) with $10 \%$ fetal bovine serum (FBS) and $500 \mu \mathrm{g} / \mathrm{ml}$ of penicillin-streptomycin.

Isolation of mouse hepatocytes and preparation of conditioned medium. Mouse hepatocytes were isolated from E13.5, E15.5, E17.5 and E19.5 C57BL/6JJcI mice (Charles River Laboratories, Willmington, MA, USA), either newborn (within 2 weeks) or 
adult (12 weeks) C57BL/6JJcI mouse (Nihon Clea). Briefly, when the mice were sacrificed, the liver was removed, minced into small sections, collected with hepatocyte-culture medium, centrifuged at $85 \mathrm{x} \mathrm{g}$ for $3 \mathrm{~min}$ to remove cell debris, incubated with $0.1 \%$ collagenase type IV (Worthington Biochemical Corp.,) and agitated in a water bath at $37^{\circ} \mathrm{C}$ for $30 \mathrm{~min}$. Subsequently, the mixtures were added to hepatocyte culture medium followed by centrifugation at $800 \mathrm{rpm}$ for $3 \mathrm{~min}$ to remove cell debris, damaged cells and non-parenchymal cells. The remaining liver parenchyma was collected in hepatocyte culture medium, passed through a $70-\mu \mathrm{m}$ sterile filter (Corning Inc.) and cultured at $500,000 / \mathrm{ml}$ at $37^{\circ} \mathrm{C}$ and $5 \% \mathrm{CO}_{2}$. The hepatocyte culture medium consisted of DMEM-high glucose with $10 \% \mathrm{FBS}, 500 \mu \mathrm{g} / \mathrm{ml}$ of penicillin-streptomycin, $0.5 \mu \mathrm{g} / \mathrm{ml}$ insulin (Sigma-Aldrich, St. Louis, MO, USA), $1 \mu \mathrm{M}$ dexamethasone (Sigma-Aldrich), $10 \mathrm{ng} / \mathrm{ml}$ epidermal growth factor (Peprotech, Inc., Rocky Hill, NJ, USA) and $200 \mu \mathrm{M}$ ascorbic acid (Sigma-Aldrich). Culture media were replaced every 2 days. The conditioned medium was generated according to the previous study by Kawamoto et al (12). In detail, these hepatocytes grew to $\leq 50 \%$ confluence with hepatocyte culture medium. Subsequently, the hepatocyte culture medium was replaced with fresh medium on day 2 . After a 48 -h culture period, the medium was collected (\#1) and replaced with fresh medium. Subsequently, CMs were collected every $48 \mathrm{~h}$ incubation (\#2). These conditioned media (\#1 and \#2) were pooled and filtered using a bottle-top filter (Corning, Inc.) to remove cells and debris. Conditioned medium samples were frozen at $-20^{\circ} \mathrm{C}$ for later use. Induction of hepatogenic differentiation of mouse ADSCs was by hepatocyte-conditioned medium. For evaluation of the hepatogenic differentiation ability, mouse ADSCs were cultured with these types of hepatocyte-conditioned medium at $37^{\circ} \mathrm{C}$ and $5 \% \mathrm{CO}_{2}$. These cells were maintained by media exchange every 2-3 days for 2 and 4 weeks, and subsequently they were collected for RNA isolation.

Reverse transcription-polymerase chain reaction (RT-PCR). Total RNA was isolated from samples using TRIzoL Reagent (Invitrogen Life Technologies, Carlsbad, CA, USA), following the manufacturer's protocol, and was treated with ReverTra Ace (Toyobo Co., Ltd., Osaka, Japan) to generate cDNA. Subsequently, PCR amplification was performed for mouse hepatocyte nuclear factor $4, \alpha(H N f 4 \alpha)$, $\alpha$-fetoprotein $(A f p)$, glucose-6-phosphatase (G6p), albumin (Alb), cytokeratin 19 (Ck19), Ck7 and sex-determining region-Y-box 9 (Sox9). The RT-PCR products ware analyzed by $1 \%$ agarose gel electrophoresis and visualized with ethidium bromide.

\section{Results}

Differentiation of ADSCs. To investigate the effect of conditioned medium from mouse hepatocyte, ADSCs were cultured using the conditioned medium (Fig. 1). Subsequently the gene expression pattern was analyzed. The hepatocyte marker genes $H n f 4 \alpha, A f p$ and $G 6 P$ were not expressed in undifferentiated and conditioned medium-treated ADSCs (Fig. 2). Alb expression can be observed at an extremely low level in adult hepatocyte-derived conditioned medium-treated ADSCs (Fig. 2). These data suggested that the conditioned medium from mouse hepatocyte could not induce mouse ADSCs to

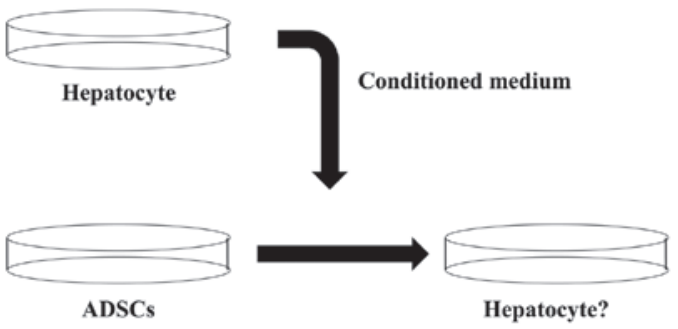

Figure 1. Overview of the experimental design. ADSCs were cultured in hepatocyte-derived conditioned medium to differentiate into hepatocytes. ADSCs, adipose-derived stem cells.

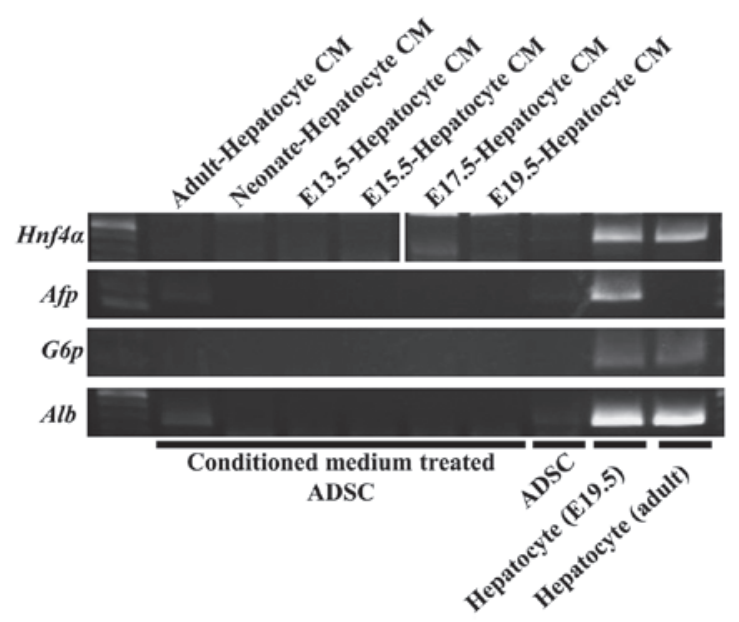

Figure 2. Polymerase chain reaction analysis of hepatocyte marker genes. Gene expression analysis of $H n f 4 \alpha, A f p, G 6 p$ and $A l b$. Hnf $4 \alpha$, hepatocyte nuclear factor 4, $\alpha$; Afp, $\alpha$-fetoprotein; G6p, glucose-6-phosphatase; Alb, albumin; ADSCs, adipose-derived stem cells; CM, conditioned medium.

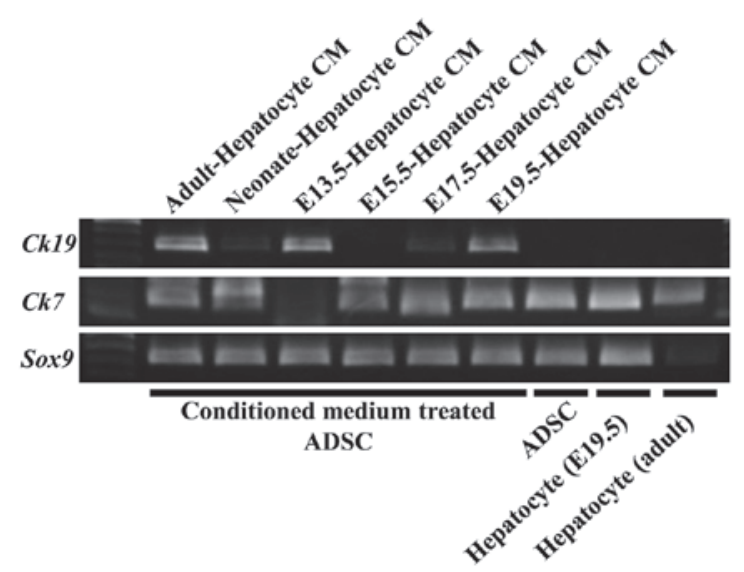

Figure 3. Polymerase chain reaction analysis of bile cells marker genes. Gene expression analysis of $C k 19, C k 7$ and Sox9. Ck19, cytokeratin 19; Sox9, sex-determining region-Y-box 9; ADSCs, adipose-derived stem cells; CM, conditioned medium.

hepatocyte. By contrast, bile cells marker genes were expressed in conditioned medium-treated ADSCs. Ck19 was expressed in ADSCs cultured in adult, E13.5, and E19.5 mouse hepatocyte derived conditioned medium (Fig. 3). Ck7 was expressed in ADSCs cultured in adult, neonate, E13.5, E15.5 and E19.5 mouse hepatocyte-derived conditioned medium (Fig. 3). Furthermore, Sox9, which was expressed in various types of 
stem cells or progenitor cells, was expressed in undifferentiated ADSCs and conditioned medium-treated ADSCs (Fig. 3). These data suggested that the conditioned culture medium from mouse fetal hepatocyte could induce mouse ADSCs to differentiate to bile cell lineages and/or their progenitor cells.

\section{Discussion}

The present study showed that conditioned medium derived from hepatocytes could induce ADSCs to bile cells. In mouse embryonic development, CCAAT-enhancer-binding protein $\alpha$ $(\mathrm{C} / \mathrm{EBP} \alpha)$ is known as a critical transcription factor that induces hepatoblasts into hepatocytes (13). Downregulation of $\mathrm{C} / \mathrm{EBP} \alpha$ is the most important event in differentiation into bile cells. $\mathrm{C} / \mathrm{EBP} \alpha$-knockout mice could not develop mature hepatocyte cells, and all the cells that should have been hepatocytes were bile cells (14). Furthermore, it was reported that transforming growth factor $\beta$ (TGF $\beta$ )/activin and Notch signaling were important for developing bile cells. Therefore, it was considered that the conditioned medium derived from hepatocytes may contain the $\mathrm{C} / \mathrm{EBP} \alpha$ inhibitor, TGF $\beta /$ activin or Notch (15-17). In conclusion, analysis of the factors in the conditioned medium will lead to the development of efficient bile cell differentiation culture medium and regenerative therapy for the bile duct.

\section{Acknowledgements}

The authors thank all the members of the laboratory for the discussion of the study and technical assistance. The present study was supported in part by a Grant-in-Aid for Scientific Research from the Ministry of Education, Culture, Sports, Science, and Technology and P-DIRECT; a Grant-in-Aid from the Ministry of Health, Labor and Welfare; a grant from the National Institute of Biomedical Innovation; and a grant from the Osaka University Drug Discovery Funds. Partial support was received from the Suzuken Memorial Foundation (M.K.), the Yasuda Medical Foundation (N.N.), the Pancreas Research Foundation (K.K.), the Nakatani Foundation (H.I.), and the Nakatomi Foundation of Japan (M.K.). Institutional endowments were received partially from Taiho Pharmaceutical Co., Ltd., Evidence Based Medical Research Center, Chugai Co., Ltd., Yakult Honsha Co., Ltd., and Merck Co., Ltd. These funding bodies had no role in the main experimental materials and methods, supplies or expenses, study design, data collection and analysis, decision to publish, or preparation of the manuscript.

\section{References}

1. Majumdar MK, Banks V, Peluso DP and Morris EA: Isolation, characterization, and chondrogenic potential of human bone marrow-derived multipotential stromal cells. J Cell Physiol 185 98-106, 2000.
2. Zuk PA, Zhu M, Mizuno H, Huang J, Futrell JW, Katz AJ, Benhaim P, Lorenz HP and Hedrick MH: Multilineage cells from human adipose tissue: Implications for cell-based therapies. Tissue Eng 7: 211-228, 2001.

3. Halvorsen YC, Wilkison WO and Gimble JM: Adipose-derived stromal cells - their utility and potential in bone formation. Int J Obes Relat Metab Disord 24 (Suppl 4): S41-S44, 2000.

4. 4. Halvorsen YD, Franklin D, Bond AL, Hitt DC, Auchter C, Boskey AL, Paschalis EP, Wilkison WO and Gimble JM: Extracellular matrix mineralization and osteoblast gene expression by human adipose tissue-derived stromal cells. Tissue Eng 7: 729-741, 2001.

5. Rangappa S, Fen C, Lee EH, Bongso A and Sim EK: Transformation of adult mesenchymal stem cells isolated from the fatty tissue into cardiomyocytes. Ann Thorac Surg 75: 775-779, 2003.

6. Planat-Benard V, Silvestre JS, Cousin B, André M, Nibbelink M, Tamarat R, Clergue M, Manneville C, Saillan-Barreau C, Duriez M, et al: Plasticity of human adipose lineage cells toward endothelial cells: Physiological and therapeutic perspectives. Circulation 109: 656-663, 2004.

7. Konno M, Hamazaki TS, Fukuda S, Tokuhara M, Uchiyama H, Okazawa $\mathrm{H}$, Okochi $\mathrm{H}$ and Asashima $\mathrm{M}$ : Efficiently differentiating vascular endothelial cells from adipose tissue-derived mesenchymal stem cells in serum-free culture. Biochem Biophys Res Commun 400: 461-465, 2010.

8. Konno M, Hamabe A, Hasegawa S, Ogawa H, Fukusumi T, Nishikawa S, Ohta K, Kano Y, Ozaki M, Noguchi Y, et al: Adipose-derived mesenchymal stem cells and regenerative medicine. Dev Growth Differ 55: 309-318, 2013.

9. Banas A, Teratani T, Yamamoto Y, Tokuhara M, Takeshita F, Quinn G, Okochi H and Ochiya T: Adipose tissue-derived mesenchymal stem cells as a source of human hepatocytes. Hepatology 46: 219-228, 2007.

10. Casteilla L and Dani C: Adipose tissue-derived cells: From physiology to regenerative medicine. Diabetes Metab 32: 393-401, 2006.

11. D'Andrea F, De Francesco F, Ferraro GA, Desiderio V, Tirino V, De Rosa A and Papaccio G: Large-scale production of human adipose tissue from stem cells: A new tool for regenerative medicine and tissue banking. Tissue Eng Part C Methods 14: 233-242, 2008.

12. Kawamoto K, Yabe S, Konno M, Ishii H, Nishida N, Koseki J, Fukuda S, Tomimaru Y, Hama N, Wada H, et al: Murine insulinoma cell-conditioned medium with BETA2/Neurod1 transduction efficiently induces the differentiation of adipose-derived mesenchymal stem cells into $\beta$-Like cells both in vitro and in vivo. J Stem Cell Res Ther 4: 1000221, 2014.

13. Shiojiri N, Takeshita K, Yamasaki H and Iwata T: Suppression of C/EBP alpha expression in biliary cell differentiation from hepatoblasts during mouse liver development. J Hepatol 41: 790-798, 2004

14. Yamasaki H, Sada A, Iwata T, Niwa T, Tomizawa M, Xanthopoulos KG, Koike T and Shiojiri N: Suppression of $\mathrm{C} / \mathrm{EBPalpha}$ expression in periportal hepatoblasts may stimulate biliary cell differentiation through increased Hnf6 and Hnflb expression. Development 133: 4233-4243, 2006.

15. McCright B, Lozier J and Gridley T: A mouse model of Alagille syndrome: Notch2 as a genetic modifier of Jag1 haploinsufficiency. Development 129: 1075-1082, 2002.

16. Tanimizu N and Miyajima A: Notch signaling controls hepatoblast differentiation by altering the expression of liver-enriched transcription factors. J Cell Sci 117: 3165-3174, 2004.

17. Clotman F, Jacquemin P, Plumb-Rudewiez N, Pierreux CE, Van der Smissen P, Dietz HC, Courtoy PJ, Rousseau GG and Lemaigre FP: Control of liver cell fate decision by a gradient of TGF beta signaling modulated by Onecut transcription factors. Genes Dev 19: 1849-1854, 2005. 